\title{
Neratinib resistance and cross-resistance to other HER2-targeted drugs due to increased activity of metabolism enzyme cytochrome P4503A4
}

\author{
Susan Breslin ${ }^{1,2}$, Michelle C Lowry ${ }^{1,2}$ and Lorraine O'Driscoll ${ }^{*, 1}$ \\ ${ }^{1}$ School of Pharmacy and Pharmaceutical Sciences and Trinity Biomedical Sciences Institute, Trinity College Dublin, Dublin, Ireland
}

Background: Neratinib is in Phase 3 clinical trials but, unfortunately, the development of resistance is inevitable. Here, we investigated the effects of acquired neratinib resistance on cellular phenotype and the potential mechanism of this resistance.

Methods: Neratinib-resistant variants of HER2-positive breast cancer cells were developed and their cross-resistance investigated using cytotoxicity assays. Similarly, sensitivity of trastuzumab-resistant and lapatinib-resistant cells to neratinib was assessed. Cellular phenotype changes were evaluated using migration, invasion and anoikis assays. Immunoblotting for HER family members and drug efflux pumps, as well as enzyme activity assays were performed.

Results: Neratinib resistance conferred cross-resistance to trastuzumab, lapatinib and afatinib. Furthermore, the efficacy of neratinib was reduced in trastuzumab- and lapatinib-resistant cells. Neratinib-resistant cells were more aggressive than their drugsensitive counterparts, with increased CYP3A4 activity identified as a novel mechanism of neratinib resistance.

Conclusions: The potential of increased CYP3A4 activity as a biomarker and/or target to add value to neratinib warrants investigation.

Targeted therapies have substantially improved treatment of HER2-overexpressing cancers. These include trastuzumab (Vogel et al, 2002), pertuzumab (Agus et al, 2005) and lapatinib (Burris et al, 2005), with neratinib, afatinib and T-DM1 currently undergoing clinical trials. Neratinib is an irreversible EGFR, HER2 and HER4 inhibitor (Bose and Ozer, 2009). A Phase 1 trial of neratinib showed an acceptable safety profile with anti-tumour activity observed for advanced solid tumours (Wong et al, 2009). Phase 2 data showed substantial clinical activity in terms of progressionfree survival and reduced tumour burden (Burstein et al, 2010). Swaby et al (2009) indicates that dual administration of neratinib with trastuzumab is well-tolerated and produces a clinical response. Other trials investigating neratinib efficacy are also underway.
Innate and acquired resistance and cross-resistance to anticancer medication dominates as the main reason that anti-cancer drugs fail in the clinic (Gottesman, 2002; Raguz and Yagüe, 2008; Germano and O'Driscoll, 2009; Tan et al, 2010). Continued efforts to decipher the mechanism(s) of resistance are necessary to predict and circumvent this problem.

An understanding of the ability of cancer cells to acquire neratinib resistance and the associated effects on cell behaviour is lacking. After developing novel neratinib-resistant cell variants of HER2-positive breast cancer cell lines, here, we investigated if neratinib-resistant cells are cross-resistant to other drugs typically used for breast cancer; explored phenotypic changes that may have developed with neratinib resistance; and elucidated mechanisms that may be responsible for neratinib resistance.

*Correspondence: Professor L O’Driscoll; E-mail: lodrisc@tcd.ie

${ }^{2}$ These authors contributed equally to this work.

Received 28 July 2016; revised 4 December 2016; accepted 15 December 2016; published online 2 February 2017

(C) 2017 Cancer Research UK. All rights reserved 0007-0920/17 


\section{MATERIALS AND METHODS}

Cell culture. HCC1954 and EFM192A HER2-positive breast cancer cell lines (termed HCC1954-Par and EFM192A-par) were obtained from ATCC and Leibniz-Institut DSMZ, respectively, and were cultured in RPMI-1640 (Sigma-Aldrich, St Louis, MO, USA) with $10 \%$ FBS (Gibco, Carlsbad, CA, USA) and $1 \%$ L-glutamine (Sigma-Aldrich). HCC1954 neratinib-resistant (HCC1954-NR) and EFM192A neratinib-resistant (EFM192A$\mathrm{NR}$ ) variants were established by continuous exposure to increasing concentrations of neratinib (5-250 nM for HCC1954-NR cells, 5-80 nM for EFM192A-NR cells) for several months. Lapatinib-resistant HCC1954 and SKBR3 cells (SKBR3-LR, HCC1954-LR) and trastuzumab-resistant SKBR3 (SKBR3-TR) cells were established as we previously described (Rani et al, 2014). Anti-cancer drugs were obtained from Sequoia Research (Pangbourne, UK) and St James's Hospital. Ketoconazole was purchased and obtained from Sigma-Aldrich.

Toxicity assays. The $\mathrm{IC}_{50}$ values of neratinib, afatinib, lapatinib, trastuzumab and docetaxel for all cell variants were determined. Using 96-well plates (Sigma-Aldrich), HCC1954-Par, HCC1954-NR and HCC1954-LR were seeded at $3 \times 10^{3}$ cells per well; EFM192A-Par and EFM192A-NR, at $5 \times 10^{3}$ cells per well; and SKBR3-LR and SKBR3-TR cells at $1 \times 10^{4}$ cells per well. After $24 \mathrm{~h}$, cells were exposed to relevant drugs (Supplementary Material) for 5 days. The effect on cells was assessed using acid phosphatase assay (Breslin and O’Driscoll, 2016).

Migration assays. HCC1954-Par and HCC1954-NR were seeded at $1 \times 10^{5}$ cells in RPMI (with $1 \%$ FBS) in cell culture inserts (BD Biosciences, Oxford, UK) in 24-well plates (Sigma-Aldrich). About $400 \mu \mathrm{l}$ of complete RPMI was placed under inserts. Cells were allowed to migrate for $24 \mathrm{~h}$ before evaluating as previously described (O'Brien et al, 2015). As EFM192A variants did not migrate through inserts, as an alternative cells were seeded at $5 \times 10^{5}$ cells per well in 24 -well plates and wound-scratch assays performed as previously described (O’Brien et al, 2015). For the equivalent wound healing assay with the HCC1954-Par and HCC1954-NR cell variants, cells were seeded at $2 \times 10^{4}$ cells per well in 24-well plates.

Invasion assays. Performed as for migration assays, but inserts were first coated with extracellular matrix (Sigma-Aldrich)
(Corcoran et al, 2012) and cells were allowed to invade over $48 \mathrm{~h}$.

Anoikis assays. All cell variants were seeded at $5 \times 10^{4}$ cells per $\mathrm{ml}$ into poly-HEMA-coated (Sigma-Aldrich) 24-well plates; with 95\% ethanol-coated wells as controls. After $48 \mathrm{~h}, 100 \mu \mathrm{l}$ of alamar blue (BioRad, Hercules, CA, USA) was added for $5 \mathrm{~h}$ before reading at $570 \mathrm{~nm}$.

Immunoblots. Cell pellets were lysed using cell extraction buffer (Invitrogen, Carlsbad, CA, USA) supplemented with protease inhibitor cocktail (Roche, Basel, Switzerland). Protein was quantified using Bio-Rad protein assay (Bio-Rad, Hercules, CA, USA). About $30-50 \mu \mathrm{g}$ protein was separated using SDS gels and transferred onto PVDF (Bio-Rad). Blots were incubated overnight with primary antibodies at $4{ }^{\circ}$ C: HER2 (Calbiochem, San Diego, CA, USA); EGFR, HER3 and HER4 (Cell Signalling, Beverly, MA, USA); PGP, BCRP, CYP3A4 (Santa Cruz, Dallas, TX, USA) and $\beta$-actin (Sigma-Aldrich). Appropriate secondary antibodies were applied for $1 \mathrm{~h}$ at room temperature before developing using Immobilon Western Chemiluminescent HRP substrate (Millipore, Billerica, MA, USA).

CYP3A4 activity. HCC1954-Par and HCC1954-NR were seeded at $3 \times 10^{3}$ cells per well, and EFM192A-Par and EFM192A-NR were seeded at $5 \times 10^{3}$ cells per well in 96-well plates. Forty-eight hours post seeding, P450-Glo CYP3A4 (Promega, Madison, WI, USA) assay was performed by removing medium, adding Luciferin-IPA solution, and incubated at $37^{\circ} \mathrm{C}$ for $1 \mathrm{~h}$ before adding $50 \mu \mathrm{l}$ of luciferin detection reagent. After $20 \mathrm{~min}$ at room temperature, solution from each well was transferred to a white opaque 96-well plate and read using a Mithras LB-940 (Berthold Technologies, Bad Wildbad, Germany). To block CYP3A4 activity, HCC1954-NR cells were seeded at $3 \times 10^{3}$ cells per well and EFM192A-NR cells were seeded at $5 \times 10^{3}$ cells per well in 96-well plates. After $24 \mathrm{~h}$, cells were exposed to $40 \mathrm{~nm}$ ketoconazole alone or in combination with neratinib (325 nM for HCC1954-NR cells; $46.7 \mathrm{~nm}$ for EFM192A-NR cells) treatments for 5 days. The effect on cells was assessed using acid phosphatase assay.

\section{RESULTS}

Neratinib-resistant variants. Once established as neratinib-resistant, HCC1954-NR and EFM192A-NR cells were 6.5-6.8-fold increase in resistance, respectively, compared with their age-

Table 1. IC 50 values for HER2-targeted drugs and docetaxel in HCC1954-Par, HCC1954-NR, EFM192A-Par and EFM192A-NR cells with corresponding fold difference, showing that neratinib-resistant cells are also cross-resistant to other HER2-targeted drugs, but not docetaxel

\begin{tabular}{|c|c|c|c|c|}
\hline \multicolumn{5}{|c|}{$\mathrm{IC}_{50}$ and fold difference for HCC1954 and EFM192A parent and neratinib-resistant cell variants } \\
\hline Neratinib & $49 \mathrm{~nm}$ & $325 \mathrm{~nm}$ & $6.5 \pm 0.4$ & $1.08 \times 10^{-4}$ \\
\hline Lapatinib & $273 \mathrm{~nm}$ & $2.7 \mu \mathrm{m}$ & $10 \pm 0.8$ & $3.7 \times 10^{-7}$ \\
\hline Trastuzumab & Innate resistance & Innate resistance & NA & NA \\
\hline Neratinib & $6.8 \mathrm{~nm}$ & $46.7 \mathrm{~nm}$ & $6.8 \pm 0.3$ & $5.1 \times 10^{-5}$ \\
\hline Afatinib & $151.3 \mathrm{~nm}$ & $5.1 \mu \mathrm{m}$ & $34.6 \pm 4.4$ & 0.002 \\
\hline Lapatinib & $50 \mathrm{~nm}$ & $7.97 \mu \mathrm{M}$ & $162.9 \pm 22$ & $4 \times 10^{-6}$ \\
\hline Trastuzumab & $>500 \mu \mathrm{g} \mathrm{ml}^{-1}$ & $>500 \mu \mathrm{g} \mathrm{ml}^{-1}$ & NA & NA \\
\hline Docetaxel & $2.6 \mathrm{~nm}$ & $2.7 \mathrm{~nm}$ & $1.03 \pm 0.07$ & 0.692 \\
\hline
\end{tabular}


matched controls. The age-matched control cells are HCC1954-Par and EFM192A-Par cells, which were routinely cultured in parallel with their counterparts that were developing neratinib resistance (Table 1).

Cross-resistance. Both HCC1954-NR and EFM192A-NR cells showed substantial cross-resistance to afatinib and lapatinib, compared with their age-matched controls (Table 1). EFM192APar and EFM192A-NR are insensitive to trastuzumab, that is, both variants maintained $>80 \%$ viability in $500 \mu \mathrm{g} \mathrm{ml}^{-1}$ trastuzumab. Cross-resistance to docetaxel did not occur.

Considering cross-resistance to neratinib of lapatinib-resistant and trastuzumab-resistant cells (Table 2), HCC1954-LR and SKBR3-LR cells demonstrated $\sim 2$-fold and 15-fold crossresistance to neratinib compared with respective parent cells, whereas SKBR3-TR cells exhibited 3.3-fold increase in neratinib resistance.

Increased cell aggression. HCC1954-NR cells were significantly more migratory than HCC1954-Par by 1.3-fold (when assessed using transwell assays). Using the wound healing assay, HCC1954-NR cells demonstrated 21\% increased wound closure when compared with HCC1954-Par (Figure 1A), whereas EFM192A-NR demonstrated $17 \%$ increased wound closure compared with EFM192A-Par cells (Figure 1A). HCC1954-NR cells were also 1.3-fold more invasive than HCC1954-Par cells (Figure 1B). Furthermore, HCC1954-NR cells were more resistant to anoikis with only $2.8 \pm 0.2 \%$ of HCC1954-NR cell death, compared with $12 \pm 1.7 \%$ of HCC1954-Par cells. Similarly for EFM192A-NR cells, where only $24.7 \pm 1.1 \%$ of EFM192A-NR cells died compared with $33.7 \pm 0.8 \%$ of EFM192A-Par cells (Figure 1C).

Effects on drug targets and transporters. Drug targets and drug transporters are often altered in drug-resistant cells. As indicated in Figure 2, expression of the entire EGFR family was significantly reduced in both neratinib-resistant variants compared with drugsensitive parents; if expressed at all. On the basis of the densitometry analysis of $n=3$ independent immunoblots for each protein and where total expression in parental cells was always set at an arbitrary value of 1, EGFR was decreased in HCC1954-NR cells to $0.66 \pm 0.05$, whereas EGFR is undetected in EFM192A cells. HER2 expression was decreased to $0.45 \pm 0.07$ in HCC1954-NR cells and $0.59 \pm 0.14$ in EFM192A-NR cells. HER3 was decreased to $0.75 \pm 0.04$ in HCC1954-NR cells and $0.71 \pm 0.03$ in EFM192A-NR cells. Finally, HER4 was undetectable in HCC1954 variants and was decreased to $0.52 \pm 0.08$ in EFM192A-NR cells compared with controls.

\section{Table 2. IC ${ }_{50}$ values for neratinib in HCC1954-Par and -LR,} SKBR3-Par, -LR and -TR cells with corresponding fold difference values, showing that cells with acquired resistance to lapatinib and trastuzumab are also cross-resistant to neratinib

\begin{tabular}{|c|c|c|c|}
\hline \multicolumn{4}{|c|}{$\begin{array}{c}\text { Sensitivity of lapatinib resistance and trastuzumab resistance } \\
\text { cells to neratinib }\end{array}$} \\
\hline \multicolumn{2}{|c|}{ Neratinib $\left(\mathrm{IC}_{50}\right)$} & $\begin{array}{c}\text { Fold } \\
\text { difference }\end{array}$ & $P$-value \\
\hline HCC1954-Par & HCC1954-LR & & \\
\hline $53 \mathrm{~nm}$ & $91 \mathrm{~nm}$ & $1.7 \pm 0.1$ & 0.001 \\
\hline SKBR3-Par & SKBR3-LR & & \\
\hline $4.7 \mathrm{~nm}$ & $69.3 \mathrm{~nm}$ & $15.3 \pm 3.2$ & 0.002 \\
\hline SKBR3-Par & SKBR3-TR & & \\
\hline $4 \mathrm{~nm}$ & $15 \mathrm{~nm}$ & $3.3 \pm 0.2$ & $2.4 \times 10^{-4}$ \\
\hline
\end{tabular}

P-glycoprotein (PGP) expression was significantly decreased in HCC1954-NR and EFM192A-NR compared with control cells; by $0.36 \pm 0.07$ and $0.42 \pm 0.04$, respectively. Breast cancer-resistant protein (BCRP) expression was also decreased in HCC1954-NR and EFM192A-NR cells to $0.72 \pm 0.05$ and $0.74 \pm 0.04$, respectively.

CYP3A4 activity. Although CYP3A4 protein expression levels did not change significantly between the drug-resistant and drug-sensitive counterparts (Supplementary Figure 1), CYP3A4 activity was significantly increased in both the neratinib-resistant cell line variants (Figure 3A). Specifically, the HCC1954-NR cells had 2.9 \pm 0.3 -fold increased CYP3A4 activity when compared with HCC1954-Par cells. Similarly, EFM192A-NR cells displayed $1.5 \pm 0.2$-fold increased CYP3A4 activity compared with EFM192A-Par control cells. Efforts to block CYP3A4 activity using ketoconazole at a final concentration of $40 \mathrm{~nm}$ - to establish if this could help to at least partially restore neratinib sensitivity. Ketoconazole alone had no effects on cell viability but, when added with neratinib, ketoconazole induced a small (4.4\% for HCC1954-NR; 17.4\% for EFM192A-NR) but significant restoration of neratinib sensitivity (Figure $3 \mathrm{~B}$ ).

\section{DISCUSSION}

It is estimated that $\sim 70 \%$ of breast cancer patients with HER2overexpressing tumours are either innately resistant or acquire resistance to HER2-targeted drugs (Arribas et al, 2011). So, although data from clinical trials of neratinib indicates that many patients are gaining initial benefit, there is a gap in available information on the effects of neratinib resistance in cells; when that, inevitably, develops. For this reason, studies performed over the past number of years have been trying to understand the mechanism(s) of neratinib resistance, in order that it may be predicted, prevented or reversed. In 2012, using SKBR3 as a cell line model and what they described as a genome-wide functional RNAi screen, Seyhan et al (2012) reported on multiple genes whose inhibition was associated with neratinib resistance. In 2014, from pre-clinical in vitro and in vivo studies and analysis of $\sim 3500$ patients' specimens, we identified Neuromedin $U$ as associated with poor outcome for patients with HER2-overexpresing tumours and our pre-clinical studies indicated overexpression of $\mathrm{NmU}$ to be significantly associated with resistance to a range of HER2-targeted drugs including neratinib (Rani et al, 2014). In efforts to establish how Neuromedin U expression might be controlled, we found loss of miR-630 (predicted to control Neuromedin U expression) to be associated with increased expression of Neuromedin $U$ and with resistance to the HER2-targeted drugs including neratinib (Corcoran et al, 2014). In an effort to further elucidate other mechanisms of neratinib resistance, the studies described here were performed.

Neratinib-resistant cells developed here were found to be crossresistant to all other HER2-targeting drugs investigated. Interestingly, this cross-resistance is bi-directional, as both lapatinib- and trastuzumab-resistant cells are also cross-resistant to neratinib. Trends observed here have also been observed in clinical trials as Burstein et al (2010) found that drug-naive patients responded better to neratinib than patients previously treated with trastuzumab. Similarly, Awada et al (2013) reported that patients with prior exposure to lapatinib did not respond to neratinib as well as those who had no prior lapatinib exposure. Therefore, based on this novel cell line data it could be hypothesised that, unfortunately, in the case of neratinib resistance, if a patient was to suffer disease progression while being treated with neratinib, the efficacy of other HER2 drugs is compromised by the previous exposure to neratinib. 
A

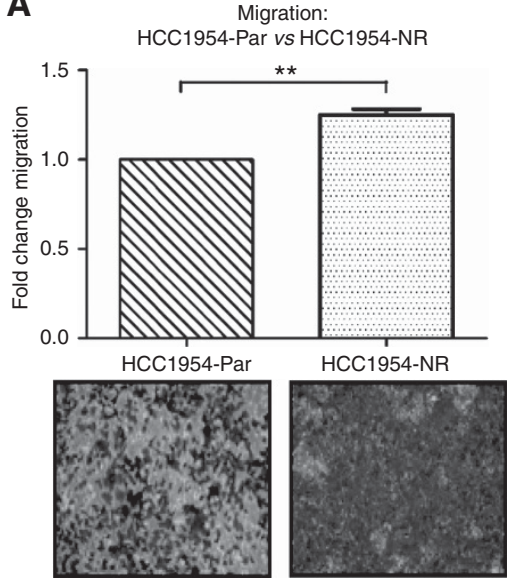

B

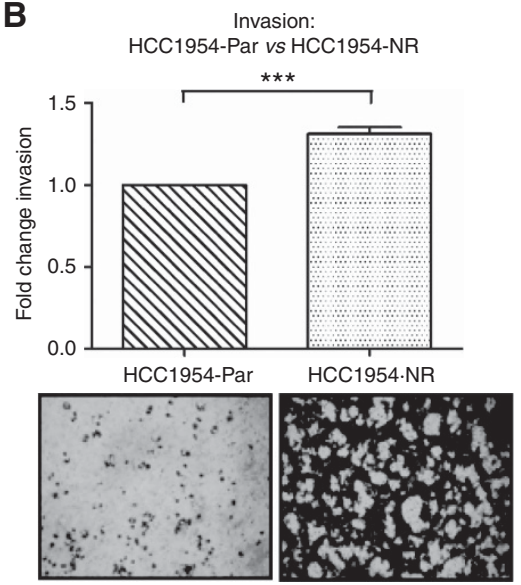

Wound healing:

HCC1954-Par vs HCC1954-NR

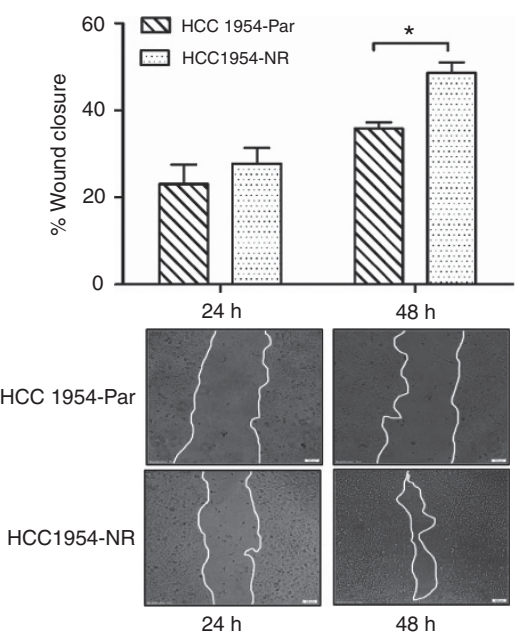

C

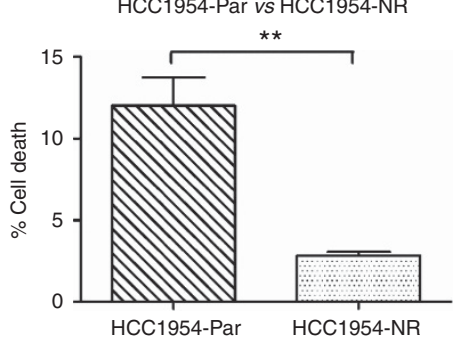

Wound healing : EFM192A-Par vs EFM192A-NR

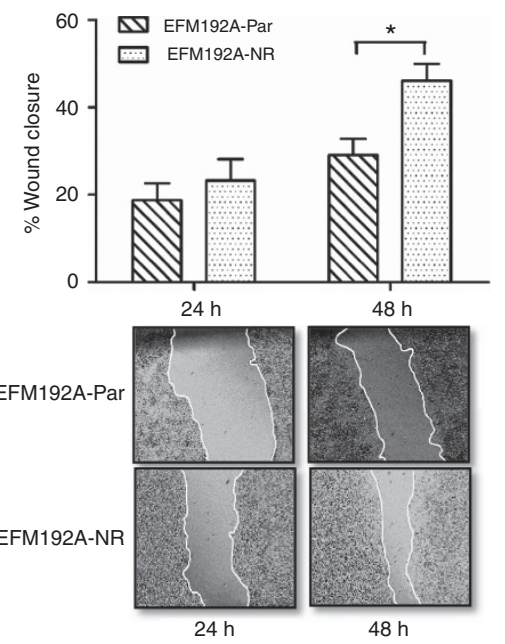

Figure 1. Acquired neratinib resistance results in phenotypic changes associated with increased cellular aggression. (A) Neratinib resistance cells are more migratory than parent cells as shown for HCC1954-NR compared with HCC1954-Par cells by both transwell assays and wound healing assay. EFM192A-Par and EFM192A-NR cells do not transverse through transwells, regardless of cell seeding density, but EFM192A-NR were shown to be more migrated than EFM192A-Par cells when using the wound healing assay; (B) HCC1954-NR cells are more invasive than HCC1954Par cells. (C) Neratinib resistance cells are more resistant to anoikis than parent cells. $n=3 \pm$ s.e.m., ${ }^{\star} P<0.05,{ }^{\star \star} P<0.01,{ }^{\star \star \star} P<0.001$.

In addition to cross-resistance to HER2-targeting drugs, HCC1954-NR and EFM192A-NR cells also developed a more aggressive phenotype, being more migratory and invasive, with increased ability to avoid anoikis. Such increased cell aggression has also been observed by ourselves and others in association with drug resistance in other cancer types and is associated with a poor prognosis for patients (Kleer et al, 2003; Lee et al, 2012); but never previously associated with neratinib.

To elucidate the mechanism that facilitates neratinib resistance, we first explored associations between neratinib resistance and neratinib's targets. All EGFR family members targeted by neratinib were reduced in the drug-resistant variants. In addition, HER3 (not targeted by neratinib but heterodimerises with HER2 (Fichter et al, 2014)) was also reduced. These observations are contrary to typical HER2 drug resistance, where EGFR and HER2 are increased in association with lapatinib (Corcoran et al, 2014; McDermott et al, 2014) and trastuzumab resistance (Browne et al, 2011). The decrease in expression of drug targets is potentially due to the irreversible binding nature of neratinib. This theory is supported by the findings of Azuma et al (2014) whose afatinib-resistant PC9 lung cancer cells had downregulated EGFR, HER2 and HER3 in comparison with drug-naive control cells.

In addition, we assessed drug efflux pumps, PGP and BCRP. P-glycoprotein is one of the most common mediators of drug resistance (Gottesman, 2002; Germano and O'Driscoll, 2009). In contrast to classical drug resistance, neratinib-resistant cells show downregulation of PGP. This may be because neratinib inhibits PGP activity and can reverse multidrug resistance in PGP overexpressing MCF7 and KBv200 cells (Zhao et al, 2012). This trend has also been observed with lapatinib (Dai et al, 2008), which was also found to reduce PGP activity; but never previously with neratinib. Overexpression of BCRP is associated with breast cancer drug resistance (Doyle and Ross, 2003). However, similarly to PGP, BCRP's reduced expression, here, suggests that it does not have a functional role in neratinib resistance.

CYP3A4, a cytochrome P450 metabolising enzyme, plays a role in the metabolism of approximately half of all drugs (Guengerich, 1999), including neratinib (Abbas et al, 2011). Abbas et al (2011) demonstrated that co-administration, to healthy adults, of ketoconazole (CYP3A4 inhibitor) with neratinib increased neratinib's peak plasma concentrations. Although this was not investigated in association with cancer, it suggested to us that alterations of CYP3A4 activity may also alter the availability of neratinib in drug resistance. Supporting this hypothesis, we observed increased CYP3A4 activity with neratinib resistance, suggesting that the increased CYP3A4 activity enhances neratinib metabolism and thereby drives neratinib resistance. Furthermore, initial efforts to block this increased CYP3A4 activity with ketoconazole in the neratinib-resistant variants showed a significant, albeit limited, restoration of neratinib sensitivity. Future 


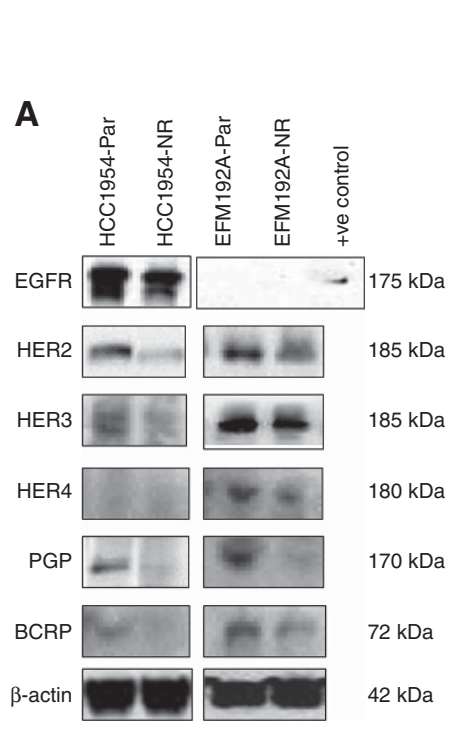

B Densitometry from HCC1954-Par \& HCC1954-NR Immunoblots (i) EGFR expression:
HCC1954-Par vs $-\mathrm{NR}$ cells
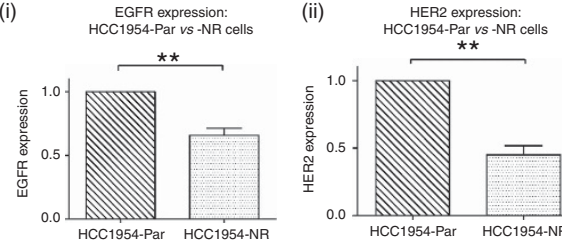

(iii)

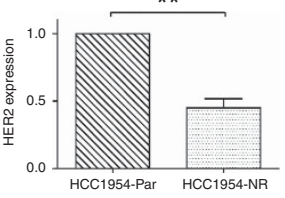

HER3 expression:
HCC1954-Par vs -NR cells

(iv)

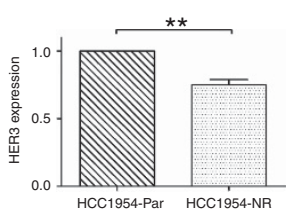

PGP expression:
(v) HCC1954-Par vs-NR cells

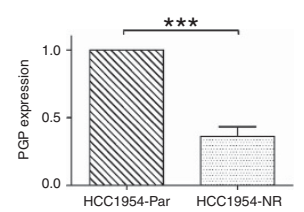

C De

(i)

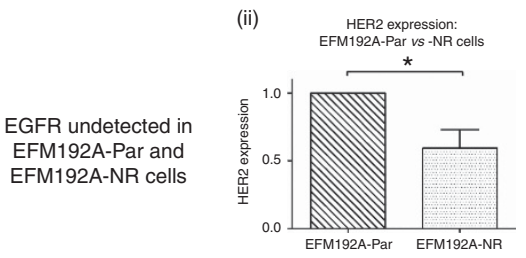

(iii)

HER3 expression:
EFM192A-Par vs -NR cells

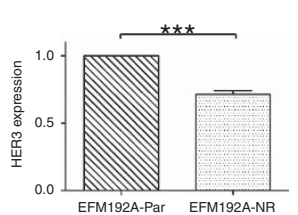

(iv) HER4 expression:

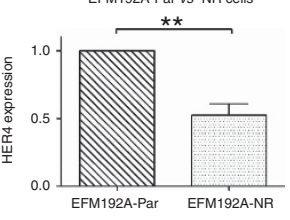

(v)

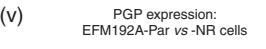

BCRP expression:
EFM192A-Par vs - NR cells
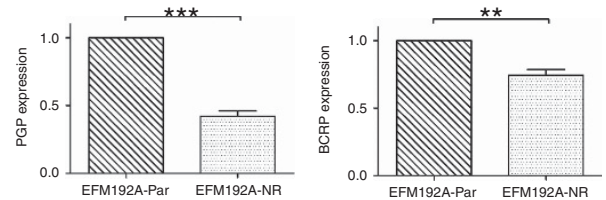

Figure 2. Associations between neratinib resistance and EGFR family members, and drug transporter. (A) Association between neratinib resistance and expression of the EGFR family, and drug efflux pumps PGP and BCRP. SKBR3 (and HCC1954) cells served as positive control in EGFR blot for EFM192A cell variants; (B) Densitometry for HCC1954-Par and HCC1954-NR immunoblots (i) EGFR; (ii) HER2; (iii) HER3; (iv) HER4; (v) PGP, and (vi) BCRP; (C) Densitometry for EFM192A-Par and EFM192A-NR immunoblots (i) EGFR; (ii) HER2; (iii) HER3; (iv) HER4; (v) PGP and (vi) BCRP. $n=3 \pm$ s.e.m., ${ }^{*} P<0.05,{ }^{* * P}<0.01,{ }^{* \star} P<0.001$.
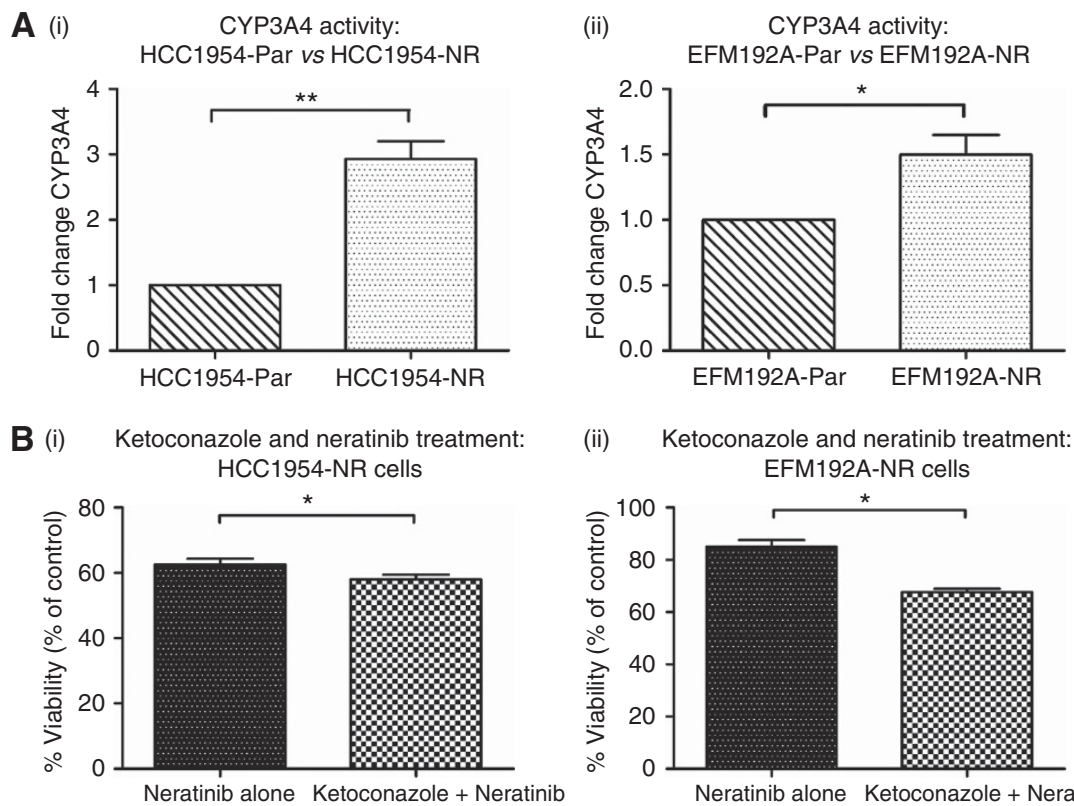

(ii) Ketoconazole and neratinib treatment:

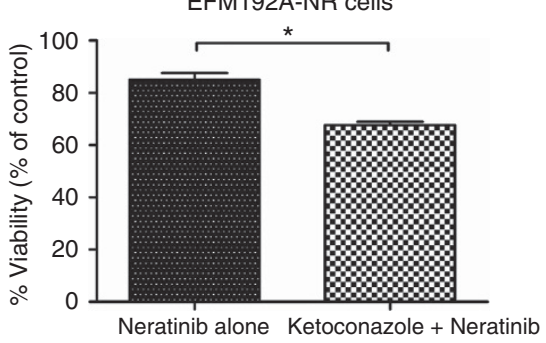

Figure 3. CYP3A4 activity in neratinib resistance compared with parent cells and partial restoration of neratinib sensitivity to former neratinib resistance cells by reducing CYP3A4 activity with ketoconazole. (A) CYP3A4 activity is substantially and significantly higher in both (i) HCC1954-NR and (ii) EFM192A-NR cells in comparison with their respective control cells. (B) Co-treatment with ketoconazole and neratinib significantly decreased cell viability in both (i) HCC1954-NR and (ii) EFM192A-NR cells when compared with neratinib treatment alone. $n=3 \pm$ s.e.m., ${ }^{\star} P<0.05,{ }^{\star \star} P<0.01$.

studies optimising the ketoconazole concentration and sequencing time of ketoconazole prior to neratinib may achieve a more marked re-sensitisation to neratinib.

This first study of neratinib resistance shows that its development confers resistance to a range of HER2 drugs. P-glycoprotein and BCRP apparently do not play functional roles in this resistance. The reduced/loss of expression of HER2 family members - thus their reduced availability for drug targeting - may be a contributing factor. Of particular interest, however, is the increased CYP3A4 activity. Further investigations of CYP3A4 activity as a possible predictive biomarker of response and as a target to circumvent resistance (and thus add value to neratinib) are now warranted. 


\section{ACKNOWLEDGEMENTS}

This work was supported by the Irish Cancer Society's BreastPredict (CCRC13GAL); the Marie Keating Foundation; Trinity Foundation, Development and Alumni; and HEA's PRTLI Cycle 5.

\section{CONFLICT OF INTEREST}

The authors declare no conflict of interest.

\section{REFERENCES}

Abbas R, Hug BA, Leister C, Burns J, Sonnichsen D (2011) Pharmacokinetics of oral neratinib during co-administration of ketoconazole in healthy subjects. Br J Clin Pharmacol 71(4): 522-527.

Arribas J, Baselga J, Pedersen K, Parra-Palau JL (2011) p95HER2 and breast cancer. Cancer Res 71(5): 1515-1519.

Agus DB, Gordon MS, Taylor C, Natale RB, Karlan B, Mendelson DS, Press MF, Allison DE, Sliwkowski MX, Lieberman G, Kelsey SM, Fyfe G (2005) Phase I clinical study of pertuzumab, a novel HER dimerization inhibitor, in patients with advanced cancer. J Clin Oncol 223(11): 2534-2543.

Awada A, Dirix L, Manso Sanchez L, Xu B, Luu T, Diéras V, Hershman DL, Agrapart V, Ananthakrishnan R, Staroslawska E (2013) Safety and efficacy of neratinib (HKI-272) plus vinorelbine in the treatment of patients with ErbB2-positive metastatic breast cancer pretreated with anti-HER2 therapy. Ann Oncol 24(1): 109-116.

Azuma K, Kawahara A, Sonoda K, Nakashima K, Tashiro K, Watari K, Izumi H, Kage M, Kuwano M, Ono M, Hoshino T (2014) FGFR1 activation is an escape mechanism in human lung cancer cells resistant to afatinib, a panEGFR family kinase inhibitor. Oncotarget 5(15): 5908-5919.

Bose P, Ozer H (2009) Neratinib: an oral, irreversible dual EGFR/HER2 inhibitor for breast and non-small cell lung cancer. Expert Opin Investig Drugs 18(11): 1735-1751.

Breslin S, O'Driscoll L (2016) The relevance of using 3D cell cultures, in addition to $2 \mathrm{D}$ monolayer cultures, when evaluating breast cancer drug sensitivity and resistance. Oncotarget 7(29): 45745-45756.

Browne BC, Crown J, Venkatesan N, Duffy MJ, Clynes M, Slamon D, O’Donovan N (2011) Inhibition of IGF1R activity enhances response to trastuzumab in HER-2-positive breast cancer cells. Ann Oncol 22(1): 68-73.

Burris 3rd HA, Hurwitz HI, Dees EC, Dowlati A, Blackwell KL, O'Neil B, Marcom PK, Ellis MJ, Overmoyer B, Jones SF, Harris JL, Smith DA, Koch KM, Stead A, Mangum S, Spector NL (2005) Phase I safety, pharmacokinetics, and clinical activity study of lapatinib GW572016,

a reversible dual inhibitor of epidermal growth factor receptor tyrosine kinases, in heavily pretreated patients with metastatic carcinomas. J Clin Oncol 23(23): 5305-5313.

Burstein HJ, Sun Y, Dirix LY, Jiang Z, Paridaens R, Tan AR, Awada A, Ranade A, Jiao S, Schwartz G, Abbas R, Powell C, Turnbull K, Vermette J, Zacharchuk C, Badwe R (2010) Neratinib, an irreversible ErbB receptor tyrosine kinase inhibitor, in patients with advanced ErbB2-positive breast cancer. J Clin Oncol 28(8): 1301-1307.

Corcoran C, Rani S, O’Brien K, O’Neill A, Prencipe M, Sheikh R, Webb G, McDermott R, Watson W, Crown J, O'Driscoll L (2012) Docetaxelresistance in prostate cancer: evaluating associated phenotypic changes and potential for resistance transfer via exosomes. PLoS One 7(12): e50999.

Corcoran C, Rani S, Breslin S, Gogarty M, Ghobrial IM, Crown J, O’Driscoll L (2014) miR-630 targets IGF1R to regulate response to HER-targeting drugs and overall cancer cell progression in HER2 over-expressing breast cancer. Mol Cancer 13: 71.

Dai CL, Tiwari AK, Wu CP, Su XD, Wang SR, Liu DG, Ashby Jr CR, Huang Y, Robey RW, Liang YJ, Chen LM, Shi CJ, Ambudkar SV, Chen ZS, Fu LW
(2008) Lapatinib (Tykerb, GW572016) reverses multidrug resistance in cancer cells by inhibiting the activity of ATP-binding cassette subfamily B member 1 and G member 2. Cancer Res 68(19): 7905-7914.

Doyle L, Ross DD (2003) Multidrug resistance mediated by the breast cancer resistance protein BCRP (ABCG2). Oncogene 22(47): 7340-7358.

Fichter CD, Timme S, Braun JA, Gudernatsch V, Schöpflin A, Bogatyreva L, Geddert H, Faller G, Klimstra D, Tang L, Hauschke D, Werner M, Lassmann S (2014) EGFR, HER2 and HER3 dimerization patterns guide targeted inhibition in two histotypes of esophageal cancer. Int J Cancer 135(7): 1517-1530.

Germano S, O’Driscoll L (2009) Breast cancer: understanding sensitivity and resistance to chemotherapy and targeted therapies to aid in personalised medicine. Curr Cancer Drug Targets 9(3): 398-418.

Gottesman MM (2002) Mechanisms of cancer drug resistance. Ann Rev Med 53: 615-627.

Guengerich FP (1999) Cytochrome P-450 3A4: regulation and role in drug metabolism. Annu Rev Pharmacol Toxicol 39: 1-17.

Kleer CG, Cao Q, Varambally S, Shen R, Ota I, Tomlins SA, Ghosh D, Sewalt RG, Otte AP, Hayes DF, Sabel MS, Livant D, Weiss SJ, Rubin MA, Chinnaiyan AM (2003) EZH2 is a marker of aggressive breast cancer and promotes neoplastic transformation of breast epithelial cells. Proc Natl Acad Sci USA 100(20): 11606-11611.

Lee SY, Meier R, Furuta S, Lenburg ME, Kenny PA, Xu R, Bissell MJ (2012) FAM83A confers EGFR-TKI resistance in breast cancer cells and in mice. J Clin Invest 122(9): 3211-3220.

McDermott MS, Browne BC, Conlon NT, O'Brien NA, Slamon DJ, Henry M, Meleady P, Clynes M, Dowling P, Crown J, O’Donovan N (2014) PP2A inhibition overcomes acquired resistance to HER2 targeted therapy Mol Cancer 13: 157.

O’Brien K, Lowry MC, Corcoran C, Martinez VG, Daly M, Rani S, Gallagher WM, Radomski MW, MacLeod RA, O'Driscoll L (2015) miR-134 in extracellular vesicles reduces triple-negative breast cancer aggression and increases drug sensitivity. Oncotarget 6(32): 32774-32789.

Rani S, Corcoran C, Shiels L, Germano S, Breslin S, Madden S, McDermott MS, Browne BC, O’Donovan N, Crown J, Gogarty M, Byrne AT, O'Driscoll L (2014) Neuromedin U: a candidate biomarker and therapeutic target to predict and overcome resistance to HER-tyrosine kinase inhibitors. Cancer Res 74(14): 3821-3833.

Raguz S, Yagüe E (2008) Resistance to chemotherapy: new treatments and novel insights into an old problem. Br J Cancer 99(3): 387-391.

Swaby R, Blackwell K, Jiang Z, Sun Y, Dieras V, Zaman K, Zacharchuk C, Powell C, Abbas R, Thakuria M (2009) Neratinib in combination with trastuzumab for the treatment of advanced breast cancer: a Phase I/II study. J Clin Oncol 27(15s suppl): abstr 1004.

Seyhan AA, Varadarajan U, Choe S, Liu W, Ryan TE (2012) A genome-wide RNAi screen identifies novel targets of neratinib resistance leading to identification of potential drug resistant genetic markers. Mol Biosyst 8(5): 1553-1570.

Tan DS, Gerlinger M, Teh BT, Swanton C (2010) Anti-cancer drug resistance: understanding the mechanisms through the use of integrative genomics and functional RNA interference. Eur J Cancer 46(12): 2166-2177.

Vogel CL, Cobleigh MA, Tripathy D, Gutheil JC, Harris LN, Fehrenbacher L, Slamon DJ, Murphy M, Novotny WF, Burchmore M, Shak S, Stewart SJ, Press M (2002) Efficacy and safety of trastuzumab as a single agent in firstline treatment of HER2-overexpressing metastatic breast cancer. J Clin Oncol 20(3): 719-726.

Wong KK, Fracasso PM, Bukowski RM, Lynch TJ, Munster PN, Shapiro GI, Jänne PA, Eder JP, Naughton MJ, Ellis MJ, Jones SF, Mekhail T, Zacharchuk C, Vermette J, Abbas R, Quinn S, Powell C, Burris HA (2009) A Phase I study with neratinib (HKI-272), an irreversible pan ErbB receptor tyrosine kinase inhibitor, in patients with solid tumors. Clin Cancer Res 15(7): 2552-2558.

Zhao XQ, Xie JD, Chen XG, Sim HM, Zhang X, Liang YJ, Singh S, Talele TT, Sun Y, Ambudkar SV, Chen ZS, Fu LW (2012) Neratinib reverses ATPbinding cassette B1-mediated chemotherapeutic drug resistance in vitro, in vivo, and ex vivo. Mol Pharmacol 82(1): 47-58.

Supplementary Information accompanies this paper on British Journal of Cancer website (http://www.nature.com/bjc) 